\title{
Conditional Discrimination Learning in Aplysia californica
}

\author{
Ruth M. Colwill, Robin A. Absher, and Mavis L. Roberts \\ Howard Hughes Medical Institute, Center for Neurobiology and Behavior, Columbia University, College of Physicians and \\ Surgeons, New York, New York 10032
}

\begin{abstract}
Two experiments examined whether the relation between a conditioned stimulus (CS) and an unconditioned stimulus (US) might be brought under the control of contextual stimuli in the invertebrate Aplysia californica. Subjects received exposure to 2 different contexts. In both experiments, a tactile CS was paired with a shock US in one of those contexts. In the other context, that tactile CS was either nonreinforced (Experiment 1) or explicitly unpaired with the shock US (Experiment 2). Responding to the CS during a subsequent test was greater in the context in which that CS had been paired with the US compared with the context in which it had been nonreinforced or unpaired. These findings are discussed in terms of theories of conditional discrimination learning.
\end{abstract}

In a standard Pavlovian conditioning experiment, an organism is confronted with a pairing of 2 cvents, onc of which, the conditioned stimulus, or CS, is used to signal the subsequent occurrence of the other event, the unconditioned stimulus, or US. Until recently, the fact that such pairings occurred in a particular environment or context was largely ignored. However, in the last few years, considerable attention has been devoted to the role that contextual stimuli play in studies of vertebrate learning. It is now well established that repeated presentations of either CSs or USs produce associations between those events and the context in which they are delivered (see Balsam and Tomie, 1985). Moreover, under some circumstances, the associations between those events and the contexts in which they are presented have been shown to influence subsequent CS-US learning (Tomie, 1976, 1981; Baker et al., 1981). Under other conditions, those associations have been observed to affect performance to a previously trained CS (Grau and Rescorla, 1984; Bouton and King, 1986). Modern theories of conditioning have acknowledged these findings in several different ways (e.g., Rescorla and Wagner, 1972; Gibbon and Balsam, 1981; Wagner, 1981; Miller and Schachtman, 1985). In several cases, contextual conditioning has been used to account for several important features of vertebrate conditioning, such as sensitivity to the contingency between the CS and the US, as well as the detrimental effects of CS and US preexposure.

\footnotetext{
Received May 4, 1987; revised Apr. 21, 1988; accepted Apr. 22, 1988.

This research was supported by funds from the Howard Hughes Medical Institute. We should like to thank M. Morris for the provision of healthy subjects and J. Sliney for his excellent care of our subjects. We are also indebted to our many colleagues for their helpful comments and enthusiastic support during the conduct of this work. We should especially like to thank Randy Gallistel, Eric Kandel, Robert Rescorla, and Saul Sternberg.

Correspondence should be addressed to Dr. Ruth M. Colwill, Department of Psychological Sciences, Purdue University, West Lafayette, IN 47907

Copyright $@ 1988$ Society for Neuroscience $0270-6474 / 88 / 124440-05 \$ 02.00 / 0$
}

Contextual learning, however, is not only manifest in the form of an association between an event and the context in which that event is embedded. There are now several observations suggesting that contexts can also become associated with the relations obtaining between 2 other events. Typically, such demonstrations arrange for the outcome of a particular CS to be conditional upon the identity of the contextual stimuli. Thus, for example, some investigators have used situations in which the context signals that one of a pair of USs will follow a CS (Asratyan, 1965) or that one of a pair of CSs will be reinforced (Asratyan, 1961; Perkins, 1983; Rescorla et al., 1985). More recently, it has been shown that the context may provide information about whether a single CS will be reinforced (Bouton and Swartzentruber, 1986). In fact, most of the analytical work in this area has made use of this very simple design, although it has usually bcen implemented with long-duration discrete stimuli designed to mimic environmental stimuli (Ross and Holland, 1981; Holland, 1983; Ross, 1983; Rescorla, 1985, 1986). The fact that responding to a conditioned stimulus is modulated by the identity of the contextual stimuli (whether natural or artificial) has been taken as evidence that contexts may exercise some sort of modulatory control over the association between the CS and the US.

The ability to learn about contextual stimuli does not appear to be a unique feature of vertebrate learning. We have recently demonstrated that the opisthobranch mollusc Aplysia californica is able to form associations between a conventional US, an electric shock, and the context in which that US is presented. Furthermore, we have shown that this context-US association can be extinguished by nonreinforced exposure to the context. Finally, we have been able to obtain some suggestive evidence that the context-US association might retard new learning in which that US is signaled by some other stimulus (Colwill et al., 1988).

The similarities between these results and those reported for vertebrates encouraged us to explore the possibility that contexts might also control CS-US relations in this invertebrate preparation. Such a demonstration would have merit for 2 reasons. First, it would expand the range of learning abilities that have been documented for Aplysia californica. To date, most studies have focused on situations in which simple relations are arranged between 2 events (Carew et al., 1981, 1983; Walters et al., 1981; Hawkins et al., 1986) or between some behavior and its consequences (Hawkins et al., 1985; Cook and Carew, 1986). Evidence that responding to a CS could be controlled by the context in which that CS was presented would provide the first indication of conditional discrimination learning. Second, it would enhance the potential of this particular invertebrate species, whose nervous system is ideally suited for neurophysio- 
logical analyses of learning and memory, as a model system for the physiological analysis of vertebrate learning.

Two experiments explored whether Aplysia might learn to use a context to signal the relation between a CS and a US. Both experiments compared responding to a $\mathrm{CS}$ in 2 different contexts. In Experiment 1, the CS had signaled a shock US in one of those contexts but had been presented without shock in the other context. In Experiment 2, the CS was again paired with shock in one context but it was explicitly unpaired with that shock in the other context. In both experiments, the CS elicited a stronger conditioned response in the context in which it had been paired with the US relative to the other comparison context. That outcome suggests that the relation between the CS and the US was under contextual control.

\section{Experiment 1}

The purpose of Experiment 1 was to examine whether Aplysia could use a contextual stimulus to anticipate whether a CS would be reinforced. To this end, subjects were exposed equally often to 2 different contexts. In one context, a tactile stimulus was applied to the siphon and immediately followed by presentation of an aversive shock US to the mantle shelf; in the other context, only this tactile CS was presented. There are now many demonstrations that this kind of mild tactile siphon stimulation can serve as a signal for the subsequent delivery of a strong electric shock to the tail (e.g., Carew et al., 1981). That learning is exhibited by prolonged withdrawal of the siphon following application of the CS compared with the duration of siphon withdrawa! produced by a CS that has not been paired with the US. Differences of this sort are typically interpreted as evidence that the enhanced siphon withdrawal is dependent on pairings of the $\mathrm{CS}$ and the US and reflects the development of an association between the CS and the US. For the present study, the same index of conditioned responding was used to assess CS-US learning. Unpublished work in our laboratory has revealed that a moderate electric shock applied to the mantle shelf can serve as an effective US in a simple Pavlovian conditioning procedure.

To assess contextual control of the CS-US relation, the CS was tested in each context in the absence of any US presentations. If the subjects had learned in which context the CS was to be reinforced, there should be a substantially longer siphon withdrawal response to the CS in the context in which the CSUS pairings had occurred compared with the one in which the CS had been nonreinforced.

\section{Materials and methods}

Subjects. Eight experimentally naive Aplysia californica obtained from Sea Life Supply (Sand City, CA) served as subjects. They were housed in individual perforated pans $(20 \times 20 \times 10 \mathrm{~cm})$ that floated freely in a 200 gallon capacity tank of filtered and aerated artificial seawater (Instant Ocean) kept between 15 and $16^{\circ} \mathrm{C}$. The subjects weighed approximately $125 \mathrm{gm}$ at the start of the experiment and were maintained on a diet of laver (dried seaweed) for the duration of the study. They were fed daily in the late afternoon about an hour after the completion of experimental procedures. Uneaten food was removed the following morning before the animals were run. One week before the start of the experiment, the animals were anesthetized by immersion in cold saltwater $\left(1-3^{\circ} \mathrm{C}\right)$, and their parapodia were excised in order to provide an unobstructed view of and access to the siphon and mantle shelf.

Apparatus. Two discriminably different contexts were used. One context, Context A, consisted of a smooth, round, white plastic bowl containing a mixture of $200 \mathrm{ml}$ of artificial seawater (Instant Ocean) and 1 $\mathrm{ml}$ of Durkee brand lemon extract. The other context, Context $\mathrm{B}$, was a dark gray, rectangular chamber measuring $18.5 \times 13 \times 9.5 \mathrm{~cm}$ filled with artificial seawater (Instant Ocean). Its surface consisted of a series of narrow ridges about $0.3 \mathrm{~cm}$ wide, spaced $0.3 \mathrm{~cm}$ apart. An acrator was mounted in the rear left-hand corner to provide a localized source of mild turbulence.

A $14.5-\mathrm{cm}$-long wooden cocktail stick tapered to a fine point was applied manually to the inside surface of the siphon to produce a tactile CS. The tapered end was inserted into the funnel of the siphon and the tip was drawn gently but swiftly across the skin. The area of tissue stimulated consisted of an extremely narrow strip about $1 \mathrm{~cm}$ long. The US was an $80 \mathrm{~mA}, 60 \mathrm{~Hz}$ AC shock delivered through capillary electrodes that were applied manually to the surface of the mantle shelf.

Procedure. Each subject was exposed for one $20 \mathrm{~min}$ daily session to each of the 2 contexts for $6 \mathrm{~d}$. The 2 exposures on a given day were separated by an interval of at least $5 \mathrm{hr}$ and the order of exposure to the 2 contexts was counterbalanced. In one of the contexts, subjects received in each session a single conditioning trial in which the CS preceded delivery of the US. Both the CS and US were administered by hand with an interstimulus interval of approximately $0.5 \mathrm{sec}$. The time at which the conditioning trial was administered was varied across sessions. In the other context, the subjects received a single presentation of the CS per session. The time at which that CS was presented was determined by the same schedule used for the trial times in the paired context. For half the subjects, the CS was reinforced in Context A and nonreinforced in Context $B$; for the remaining subjects, the opposite contingencies were arranged so that the CS was reinforced in Context $B$ and nonreinforced in Context $A$.

Twenty-four hours after completion of conditional discrimination training, the duration of siphon withdrawal elicited by the CS was measured in both contexts by an experimenter blind to the conditioning historics of the animals. The tactile stimulus was applied to the siphon not less than 2 min after the subject had been placed in a context, thus sharply attenuating any disruptive effect on the siphon withdrawal reflex of recent handling. The time from CS onset to complete relaxation of the siphon was measured with a stopwatch. After $20 \mathrm{~min}$, the subject was removed from the experimental context and returned to its home tank. All subjects were tested first in Context $A$ and then, $5 \mathrm{hr}$ later, in Context $B$. Thus, half the animals were tested first in the context in which the CS-US pairings had occurred; the remaining animals received their first test in the context in which only the CS had been delivered. In order to preserve the experimental blind, no shocks were delivered during the test sessions. This also allowed a measure of the reflex elicited by siphon stimulation that was not influenced by the unconditioned effects of the USs.

\section{Results and discussion}

Figure 1 shows the median duration of siphon withdrawal elicited by the CS during testing in the context in which the CS and US had been paired (open bar) and in the context in which the CS had been delivered without reinforcement (striped bar). It is clear that the CS elicited longer siphon withdrawal responses in the context in which it had been paired with the US than in the context in which it had been nonreinforced (Wilcoxon $T(8)$ $=3, p<0.05$ ). That outcome is consistent with the view that the animals had learned in which context the CS would be reinforced.

It should be noted, however, that one could also account for these data solely in terms of simple context-US associations. Because shocks were delivered in one context but not in the other, there may have differences between the contexts in the amount of background conditioning. Indeed, we have reported elsewhere that such differences by themselves are sufficient to produce the pattern of results obtained in this experiment (Colwill et al., 1988). Although evidence from studies with vertebrates suggests that signaling the US ought to be quite effective in preventing that US from conditioning the background, we have no independent evidence that signaling prevented such learning from happening here. Consequently, in the present study, the difference in the duration of siphon withdrawal elicited by the $\mathrm{CS}$ in the 2 contexts might simply reflect differences in the amount of background conditioning of those contexts. A further 


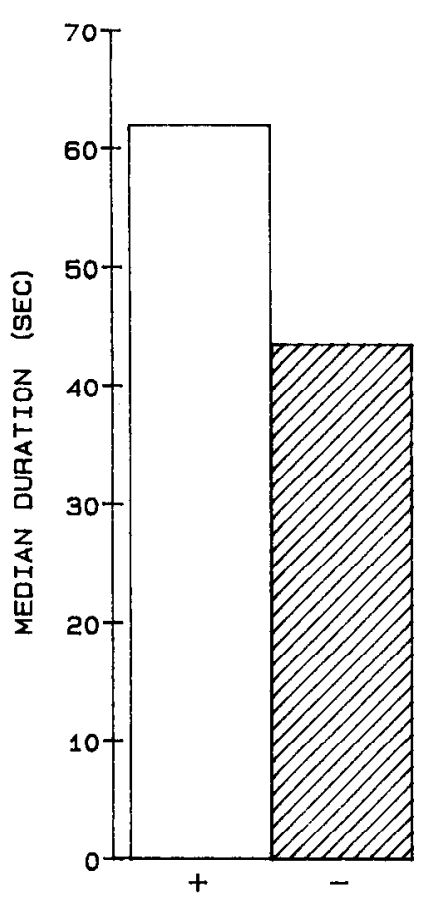

Figure 1. Experiment 1. Median duration of siphon withdrawal in response to the tactile $\mathrm{CS}$ in the context in which that $\mathrm{CS}$ had been reinforced $(+)$ and in the context in which it had been nonreinforced $(-)$.

implication of this argument is that the contexts themselves may have differentially affected the behavior of the animals. As a result the delivery of the CS during testing may not have been identical in the 2 contexts. The possibility that the results of this study may be interpreted in terms of differential background conditioning is made less plausible in the next experiment. Experiment 2 administered the shock US in both contexts while manipulating the CS-US contingency across contexts. In this way, we equated for context-US associations produced by the simple occurrence of the US.

\section{Experiment 2}

The purpose of this study was to demonstrate that contextual stimuli might acquire conditional control over a CS-US relation under circumstances that rendered an explanation based on context-US associations implausible. Subjects were exposed to 2 different contexts. As in Experiment 1, pairings of a CS and a US were delivered in one of the contexts. However, in the other context, subjects were given presentations of both the CS and the US but the arrangement was such that the events were explicitly unpaired. Thus, subjects received the same number of shock USs in each of the 2 contexts but in one those USs were preceded by the CS and in the other they were not. The consequence of this treatment was to provide the unpaired context with the opportunity to become associated with the shock US. In fact, it is quite likely that the context-US association might well have been stronger for that context than for the paired context. In the vertebrate literature, it has been widely documented that signaled USs may be less effective reinforcers than unsignaled USs (see Rescorla and Holland, 1982). Thus, one might expect the CS to reduce or block the development of background conditioning in the paired context. Finally, to assess the presence of contextual control over the CS-US association, the CS was tested in each context without any US presentations. If the subjects had learned in which context the CS was to be reinforced, siphon withdrawal should be of a longer duration in the context in which the CS-US pairings had occurred. However, if the subjects had not learned to use the contexts as conditional cues and if the differences obtained in Experiment 1 were simply the product of differential context-US associations, the duration of siphon withdrawal should be longer in the unpaired context.

\section{Materials and methods}

Subjects and apparatus. The subjects were 16 experimentally naive $A p l y$ sia californica supplied by Sea Life Supply (Sand City, CA). They were housed and maintained in a manner identical to that described for Experiment 1. The apparatus was also the same as that used in Experiment 1.

Procedure. Each subject was exposed for $20 \mathrm{~min}$ daily to each of the 2 contexts for $8 \mathrm{~d}$. On a given day, the 2 exposures were separated by an interval of about $5 \mathrm{hr}$ with the order of exposure balanced across contexts. As in Experiment 1, subjects received a single conditioning trial in one of the contexts each day. In the other context, the same CS and US were each presented once per day but they were unpaired. The order of presentation of the CS and US was balanced, and the times at which they were delivered varied across days with 2 restrictions. First, there were an equal number of CS and US presentations scheduled to occur at the same time as the conditioning episode in the paired context; and, second, the interval between the 2 events was at least $5 \mathrm{~min}$. For half the subjects, the CS and US were paired in Context $A$ and unpaired in Context $\mathbf{B}$; for the remaining subjects, the opposite contingencies were arranged.

Twenty-four hours after the final day of conditional discrimination training, the CS was tested in each context. The details of the test procedure are identical to those described in Experiment 1.

\section{Results and discussion}

The test data showing the median duration of siphon withdrawal are displayed in Figure 2. The open bar on the left shows siphon withdrawal to the CS when that CS was presented in the context in which it had been paired with the US. The striped bar on the right shows siphon withdrawal to the same CS when tested in the context in which it had been explicitly unpaired with the US. The important point to note about these data is that siphon withdrawal was considerably longer in the paired context than in the unpaired context. That difference was found to be highly significant (Wilcoxon $T(15)=13, p<0.01$ ).

These results replicate those of Experiment 1 under circumstances in which the unpaired context-US association was at least as strong, if not stronger, than the paired context-US association. Thus, regardless of the amount of background conditioning in the comparison context, the CS elicited a stronger conditioned response in the paired context. That outcome means that the enhanced response to the $\mathrm{CS}$ in the paired context cannot be explained in terms of simple summation of that CS with the background. In summary, these results reinforce the view that the animals had indeed learned to use the context as a cue for whether the CS would be reinforced.

\section{General Discussion}

These experiments demonstrate that manifestation of an excitatory association between a CS and a US can be brought under the control of a contextual stimulus in the invertebrate Aplysia californica. In one context, a tactile CS predicted the immediate presentation of an aversive shock US. In a different context, that same CS was presented without shock (Experiment 1) or explicitly unpaired with shock (Experiment 2). Knowledge of these different CS-US relations was exhibited in the form of enhanced responding to the $\mathrm{CS}$ in the paired context relative to 
the other context. That outcome implies that the context actively modulated expression of the CS-US association. Such findings highlight the potential complexity of Pavlovian conditioning processes. Moreover, they demonstrate the inadequacy of accounts of associative learning that appeal exclusively to close temporal proximity of the CS and the US for learning to occur.

To embrace the present results, the activity-dependent presynaptic facilitation model proposed by Kandel and his colleagues (e.g., Hawkins and Kandel, 1984) for associative learning in Aplysia would require substantial elaboration. That model assumes that the effective synaptic connectivity between the CS pathway and the motor neuron is strengthened by pairing the CS with a US. To permit contextual stimuli to modulate the expression of that learning, one could posit some connection between the context and the CS pathway. Such a connection might enable the CS to stimulate the motor neuron more effectively by increasing the efficacy of ncurotransmitter release from the sensory neuron. Alternatively, one might argue that the context acts postsynaptically to reduce the threshold for firing of the motor neuron.

Psychological accounts of conditional cue learning based on experiments with vertebrates have embodied the logic of some of these mechanisms. For example, some authors have suggested that the conditional cue modulates the CS-US association by shifting the threshold for activation of the US representation. Thus, one might imagine that the context in which the CS is reinforced lowers the threshold for activation of the US representation. Alternatively, the context in which the CS is either nonreinforced or unpaired with the US might raise that threshold. Either one of these mechanisms acting alone or in unison would yield the current pattern of results. The ability of conditional cues to transfer their effects to other CSs has been used to support both these options in related paradigms (Rescorla, 1985). In contrast to this view ascribing a general property to conditional cue function, Holland $(1983,1985)$ has argued for a more specific role. In his conditioning preparation, Holland has found that the conditional cue acts only on the CS with which it has been trained. Therefore, he has preferred to account for such learning by shifting the locus of action of the conditional cue from the US representation to the association between the CS and the US. Thus, applied to the present case, one might argue that the context in which the CS is reinforced increases the ability of the CS to trigger the US representation. On the other hand, it is possible that the subject has learned to withhold its response to the CS in the context in which that CS is nonreinforced. Thus, the context could inhibit the association between the CS and the US. It would be of great interest to examine the impact of contexts trained as conditional cues on responding to other CSs in Aplysia. If transfer were obtained, it would indicate some general property of the conditional cue. Moreover, such a demonstration would have the additional virtue of making it easier to rule out some of the less interesting alternative accounts of conditional discrimination performance.

The primary alternative class of accounts of conditional discrimination learning exploits existing principles of associative learning. The prototypical instance of this group is the unique cue hypothesis (Rescorla, 1972, 1973; Saavedra, 1975). In its most elementary form, this account assumes that the contexts influence perception of the CS with the result that the subject fails to recognize that it is the same CS that is presented in the different contexts. A second version which is an extension of this encoding idea is that the representation of the CS includes

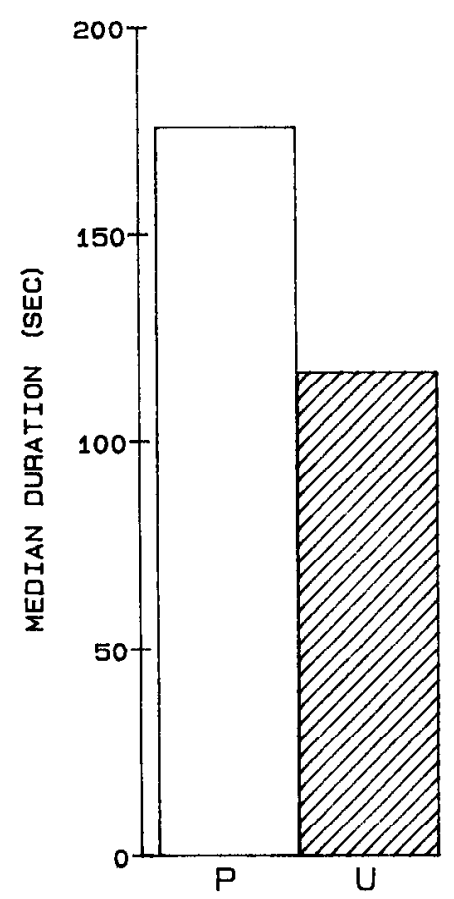

Figure 2. Experiment 2. Median duration of siphon withdrawal in response to the tactile CS when applied in the context in which that CS had been paired $(P)$ with shock US and in a context in which that CS and US had been unpaired (U).

features of the context in which that CS is presented. According to this account, each combination of the $C S$ with a different context yields a unique representation. In both cases, however, the conditional discrimination is reduced to a simple Pavlovian discrimination between 2 complex elements, one reinforced and one not. The solution of such discriminations presents no problem to Aplysia (Carew et al., 1981, 1983; Walters et al., 1981).

It turns out to be remarkably difficult, however, to distinguish empirically sophisticated versions of the unique cue hypothesis from modulatory accounts of conditional discrimination learning. One of the exciting possibilities of neurobiological analyses of these kinds of learning processes is that they may yield evidence favorable to one or other account. For instance, according to the unique cue account, a different set of sensory neuronal inputs should be activated when the $\mathrm{CS}$ is applied in the paired context relative to the unpaired context. On the other hand, the modulatory accounts would expect the same sensory inputs to be triggered by the CS but with different consequences depending on the identity of the context. The exciting prospect suggested by the present findings in Aplysia is that the complexity of conditional discrimination learning may one day be unraveled at a neurophysiological level.

\section{References}

Asratyan, E. A. (1961) The initiation and localization of cortical inhibition in the conditioned reflex arc. Ann. NY Acad. Sci. 92: 11411159.

Asratyan, E. A. (1965) Contemporary Adaptations, Reflex Activity, and the Brain, Pergamon, New York.

Baker, A. G., P. Mercier, J. Gabel, and P. A. Baker (1981) Contextual conditioning and the US preexposure effect in conditioned fear. J. Exp. Psychol. Anim. Behav. Processes 7: 109-128.

Balsam, P. D., and A. Tomie, eds. (1985) Context and Learning, Erlbaum, Hillsdale, NJ. 
Bouton, M. E., and D. A. King (1986) Effect of context on performance to conditioned stimuli with mixed histories of reinforcement and nonreinforcement. J. Exp. Psychol. Anim. Behav. Processes 12: 415.

Bouton, M. E., and D. Swartzentruber (1986) Analysis of the associative and occasion-setting properties of contexts participating in a Pavlovian discrimination. J. Exp. Psychol. Anim. Behav. Processes 12: 333-350.

Carew, T. J., E. T. Walters, and E. R. Kandel (1981) Classical conditioning in a simple withdrawal reflex in Aplysia californica. J. Neurosci. $1: 1426-1437$

Carew, T. J., R. D. Hawkins, and E. R. Kandel (1983) Differential classical conditioning of a defensive withdrawal reflex in Aplysia californica. Science 219: 397-400.

Colwill, R. M., R. A. Absher, and M. L. Roberts (1988) Context-US learning in Aplysia californica. J. Neurosci. 8: 4434-4439.

Cook, D. G., and T. J. Carew (1986) Operant conditioning of head waving in Aplysia. Proc. Natl. Acad. Sci. USA 83: 1120-1124.

Gibbon, J., and P. D. Balsam (1981) Spreading association in time. In Autoshaping and Conditioning Theory, C. M. Locurto, H. S. Terrace, and J. Gibbon, eds., pp. 219-253, Academic, New York.

Grau, J. W., and R. A. Rescorla (1984) Role of context in autoshaping. J. Exp. Psychol. Anim. Behav. Processes 10: 324-332.

Hawkins, R. D., and E. R. Kandel (1984) Is there a cell-biological alphabet for simple forms of learning? Psychol. Rev. 91: 375-391.

Hawkins, R. D., G. A. Clark, and E. R. Kandel (1985) Operant conditioning and differential classical conditioning of gill withdrawal in Aplysia. Soc. Neurosci. Abstr. 11: 796.

Hawkins, R. D., T. J. Carew, and E. R. Kandel (1986) Effects of interstimulus interval and contingency on classical conditioning of the Aplysia siphon withdrawal reflex. J. Neurosci. 6: 1695-1701.

Holland, P. C. (1983) Occasion setting in Pavlovian feature positive discriminations. In Quantitative Analyses of Behavior: Discrimination Processes, Vol. 4, M. L. Commons, R. J. Herrnstein, and A. R. Wagner, eds., pp. 183-206, Ballinger, New York.

Holland, P. C. (1985) The nature of conditioned inhibition in serial and simultaneous feature negative discriminations. In Information Processing in Animals: Conditioned Inhibition, R. R. Miller and N. E. Spear, eds., pp. 267-297, Erlbaum, Hillsdale, NJ.

Miller, R. R., and T. Schachtman (1985) The several roles of context at the time of retrieval. In Context and Learning, P. D. Balsam and A. Tomie, eds., pp. 167-194, Erlbaum, Hillsdale, NJ.
Perkins, C. C. (1983) The analysis of performance. In Biological Factors in Learning, M. D. Zeiler and P. Harzem, eds., Wiley, New York.

Rescorla, R. A. (1972) "Configural" conditioning in discrete-trial bar pressing. J. Comp. Physiol. Psychol. 79: 307-317.

Rescorla, R. A. (1973) Evidence for "unique stimulus" account of configural conditioning. J. Comp. Physiol. Psychol. 85: 331-338.

Rescorla, R. A. (1985) Inhibition and facilitation. In Information Processing in Animals: Conditioned Inhibition, R. R. Miller and N. E. Spear, eds., pp. 299-326, Erlbaum, Hillsdale, NJ.

Rescorla, R. A. (1986) Extinction of facilitation. J. Exp. Psychol. Anim. Behav. Processes 12: 16-24.

Rescorla, R. A., and P. C. Holland (1982) Behavioral studies of associative learning in animals. Annu. Rev. Psychol. 33: 265-308.

Rescorla, R. A., and A. R. Wagner (1972) A theory of Pavlovian conditioning: Variations in the effectiveness of reinforcement and nonreinforcement. In Classical Conditioning II: Current Theory and Research, A. H. Black and W. F. Prokasy, eds., pp. 64-99, AppletonCentury-Crofts, New York.

Rescorla, K. A., P. J. Durlach, and J. W. Grau (1985) Contextual learning in Pavlovian conditioning. In Context and Learning, P. D. Balsam and A. Tomie, eds., pp. 23-56, Erlbaum, Hillsdale, NJ.

Ross, R. T. (1983) Relationships between the determinants of performance in serial feature-positive discriminations. J. Exp. Psychol Anim. Behav. Processes 9: 349-373.

Ross, R. T., and P. C. Holland (1981) Conditioning of simultaneous and serial feature-positive discriminations. Anim. Learn. Behav. 9 . 293-303.

Saavedra, M. (1975) Pavlovian compound conditioning in the rabbit. Learn. Motiv. 6: 314-326.

Tomie, A. (1976) Interference with autoshaping by prior context conditioning. J. Exp. Psychol. Anim. Behav. Processes 2: 323-334.

Tomie, A. (1981) Effects of unpredictable food upon the subsequent acquisition of autoshaping: Analysis of the context blocking hypothesis. In Autoshaping and Conditioning Theory, C. M. Locurto, H. S. Terrace, and J. Gibbon, eds., Academic, New York.

Wagner, A. R. (1981) SOP: A model of automatic memory processing in animal behavior. In Information Processing in Animals: Memory Mechanisms, N. E. Spear and R. R. Miller, eds., pp. 1-47, Erlbaum, Hillsdale, NJ.

Walters, E. T., T. J. Carew, and E. R. Kandel (1981) Associative learning in Aplysia: Evidence for conditioned fear in an invertebrate. Science 211: 504-506. 